\title{
SITUACIÓN LEGAL DE LAS PERSONAS QUE PRESTAN SERVICIOS A UNA ENTIDAD RELIGIOSA*
}

\section{LEGAL SITUATION OF PEOPLE WHO PROVIDE SERVICES TO A RELIGIOUS ENTITY}

\section{Pedro Irureta Uriarte ${ }^{1}$}

\begin{abstract}
RESUMEN: La Iglesia y las confesiones religiosas nacen a la vida del Derecho a objeto de propagar una determinada imago mundi, de acuerdo a su ideario. Dicha inserción dentro del sistema jurídico provoca una serie de efectos que obligan a identificar con claridad su ámbito de autonomía constitucionalmente reconocido. Ello ocurre, por ejemplo, en lo que respecta a las vinculaciones que se producen a raíz de los servicios que distintas personas prestan a las entidades religiosas. En algunos casos, dichos servicios se explican principalmente por una adhesión al ideario religioso de la entidad sin que sea posible advertir una relación contractual propiamente dicha. En otros, surge derechamente un vínculo jurídico de trabajo regido por las normas del ordenamiento estatal.
\end{abstract}

Palabras clave: Organización de tendencia, libertad religiosa, contrato de trabajo.

ABSTRACT: The Catholic Church and the religious denominations enter legal life to propagate, according to their beliefs, a specific imago mundi. The insertion of religious entities within the legal system makes necessary to clearly identify their autonomy range constitutionally recognized. The kind of relationships arisen as a consequence of the services that different people provide to religious entities may be different. In some cases, these services are primarily determined by people adherence to the entity's beliefs without a contractual relationship. In others, a labor relationship exists ruled by the State legislation.

Key words: Tendency organization, religious freedom, work contract.

\footnotetext{
* Abreviaturas: AL (Actualidad Laboral); ADEE (Anuario de Derecho Eclesiástico del Estado); AL (Actualidad Laboral); CCAN (Código Canónico); CPR (Constitución Política de la República); CT (Código del Trabajo); DA (Documentación Jurídica); DO (Diario Oficial); EE (Estudios Eclesiásticos); PS (Persona y Sociedad); RCEC (Revista del Centro de Estudios Constitucionales); RCHD (Revista Chilena de Derecho); RDD (Revista de Derecho Valdivia); RDDPUCV (Revista de Derecho de la Pontificia Universidad Católica de Valparaíso); RDJ (Revista de Derecho y Jurisprudencia y Gaceta de los Tribunales); REDC (Revista Española de Derecho Constitucional); REDCA (Revista Española de Derecho Canónico); REDT (Revista Española de Derecho del Trabajo); RISS (Revista Iberoamericana de Seguridad Social); RL (Relaciones Laborales); RMTI (Revista del Ministerio del Trabajo e Inmigración); RPS (Revista de Política Social); TC (Tribunal Constitucional).

1 Licenciado en Derecho por la Pontificia Universidad Católica de Chile, y Doctor en Derecho por la Universidad Complutense de Madrid, Profesor titular de Derecho del Trabajo de la Universidad Alberto Hurtado. Correo electrónico: piruret@uahurtado.cl
} 


\section{INTRODUCCIÓN}

La especial configuración de las confesiones y grupos religiosos en general, nace de la propia normativa constitucional y legal que ha regulado la libertad religiosa en Chile $^{2}$. Dicha normativa ha reconocido en las Iglesias, confesiones e instituciones religiosas a figuras lo suficientemente amplias para abarcar dentro de sí a todos los sujetos colectivos religiosos susceptibles de mantener relaciones de cooperación con el Estado, y que se encuentren integradas por personas naturales que profesan una determinada $\mathrm{fe}^{3}$. A esas mismas figuras, el Estado les reconoce libertad para manifestar todas las creencias y ejercer libremente todos los cultos, pues se parte de la base que esta libertad se conecta directamente con la dignidad de la persona ${ }^{4}$.

La especial naturaleza de las entidades religiosas, no es un dato baladí al momento de calificar el vínculo con sus colaboradores. Sin perjuicio de su indudable característica como organizaciones de tendencia ${ }^{5}$, el ordenamiento jurídico les ha otorgado a estas entidades una naturaleza tal que ellas terminan desarrollando su condición empleadora bajo un especial prisma que no es posible encontrar en otro tipo de empleadores. Lo que sucede es que las entidades religiosas no pueden ser configuradas como simples manifestaciones de la libertad de empresa o de la mera iniciativa económica; por el contrario, su base constitucional se encuentra en los derechos fundamentales de los que son titulares, cuestión que hace

2 De conformidad con el artículo $19 \mathrm{~N}^{\circ} 6 \mathrm{CPR}$, el ordenamiento constitucional chileno asegura a todas las personas la libertad de conciencia, la manifestación de todas las creencias y el ejercicio libre de todos los cultos que no se opongan a la moral, las buenas costumbres o el orden público. Por otra parte, el artículo $3^{\circ}$ de la Ley $\mathrm{N}^{\circ} 19.638$ (DO de 14 de octubre de 1999), señala que el "Estado garantiza que las personas desarrollen libremente sus actividades religiosas y la libertad de las iglesias, confesiones y entidades religiosas". Para un análisis de las normas reguladoras de la libertad religiosa en Chile, véase Cortínez Castro (2010) pp. 23 y siguientes. Cfr., además, Badilla Poblete (2008) pp. 341 y ss; y Salinas Araneda (2009) pp. 499 y ss.

3 Véase artículo $4^{\circ}$ de la Ley $N^{\circ} 19.638$, de 1999.

4 Sobre la posición jurídica de las organizaciones religiosas, véase desde una perspectiva general, y entre otros, Precht Pizarro (2000b) pp. 109 y ss; Prieto Sanchis (1988) pp. 433 y ss; y Álvarez Cortina (1998) pp. 125 y ss. Este reconocimiento no solo es predicable de los sujetos colectivos sino que, también, de las personas individuales quienes gozan del derecho a la libertad religiosa desde una doble perspectiva. Por una parte, el sistema jurídico reconoce que todo individuo tiene una libertad interna que le permite asumir o no una determinada religión, pudiendo mantenerla o cambiarla de conformidad al contenido esencial de este derecho. Incluso, se le acepta la ausencia de religión. Por otra, toda persona ostenta una libertad religiosa de orden externo según la cual se le reconoce el derecho a ejercer prácticas religiosas que lo conecta con el ámbito social. En razón de lo anterior, los tribunales chilenos han configurado esta garantía de forma amplia, reconociendo en ella una facultad que tienen las personas para profesar toda clase de religiones, y también para repartir e impartir enseñanza religiosa por cualquier medio y elegir para sí o para sus hijos o pupilos, la educación religiosa o moral que esté de acuerdo con sus propias convicciones (véase sentencia de la CORTE DE Apelaciones de Concepción de 4 de marzo de 2002. RDJ T. XCIX, sección quinta (2002). Véase también sentencia del TC ROL N 567-2006, de 2 de junio de 2010. Cfr. además la sentencia de 5 de febrero de 2001, de la Corte Interamericana de Derechos Humanos, en el caso de Olmedo Bustos y otros contra el Estado de Chile, la cual concluyó que la libertad religiosa "permite que las personas conserven, cambien, profesen y divulguen su religión o sus creencias. Este derecho es uno de los cimientos de la sociedad democrática. En su dimensión religiosa, constituye un elemento trascendental en la protección de las convicciones de los creyentes y en su forma de vida."

5 Cfr., por todos, Moreno Botella (1987) p. 537. En el ámbito nacional, véase Irureta Uriarte (2003) pp. 235 y ss. 
sustentar su poder de dirección laboral, entre otros aspectos, en la propia Ley $\mathrm{N}^{\circ}$ 19.638, que estableció normas sobre la constitución jurídica de las Iglesias y organizaciones religiosas $^{6}$. Lo anterior cobra aun mayor importancia si se toma en cuenta que para la configuración empleadora de una entidad resultan irrelevante en principio sus características jurídicas o económicas: lo distintivo es su capacidad para utilizar la prestación de los servicios, independientemente de si se trata de una organización con o sin ánimo de lucro, o si tiene un fin benéfico, cultural o social.

La entidad religiosa se distingue por la existencia de una organización englobante de los miembros de una creencia religiosa, en que ellos se sienten unidos con un ser supremo al que ofrecen su culto ${ }^{7}$. Entre sus características básicas es posible advertir una organización que ostenta una creencia religiosa común ${ }^{8}$, y que cuenta con un culto y una implicación moral que obliga a los miembros de la entidad a adecuar su vida a unas reglas de conducta derivadas de su creencia. Asimismo, se distingue una finalidad de propagación doctrinaria, cuestión que termina traduciéndose en una multiplicidad de entes de diversa naturaleza que difunden una concepción del mundo inspirada en valores ideales claramente reconocibles. En consecuencia, la entidad religiosa se organiza institucionalmente en base a estos elementos; y sin ellos se desdibuja completamente, perdiendo atributos esenciales de su configuración.

El funcionamiento de las Iglesias, confesiones y entidades religiosas se verifica en estructuras organizativas en las cuales participan personas bajo distintos regímenes de vinculación. Desde luego, muchas de ellas se encuentran adscritas en razón de figuras de mera colaboración, sin que exista una voluntad especial de estructurar vínculos formales con específicas consecuencias jurídicas. También existen personas cuya identificación con el ideario religioso es tan intenso que, en la práctica, terminan representando a la propia entidad. No obstante, hay numerosos casos en que la vinculación se traduce en un específico acuerdo contractual, que en no pocas ocasiones presupone la adhesión al ideario (o al menos su no confrontación), y que exigen especificar las consecuencias jurídicas que dicha vinculación implica para el ordenamiento legal vigente.

El problema es que no existe claridad suficiente para determinar a priori si muchos de esos trabajos se realizan a título de mera benevolencia o altruismo, o por el contrario lo que existe es una prestación propia de un contrato de trabajo. También existen dificultades para determinar los límites obligacionales del colaborador, toda vez que la adhesión al ideario religioso constituye un elemento relevante para circunscribir el contenido obligacional. En esa lógica, legítimamente la institucionalidad jurídica del Estado se tensiona a objeto de determinar con claridad cuál es el régimen jurídico aplicable a esos casos; más aún, cuando se advierte que en el Derecho chileno no existe un estatuto jurídico especial que resuelva este tipo de figuras. Yno solo eso: en rigor, en el sistema nacional tampoco hay específicas normas laborales (aunque sea aisladas) a las cuales pudiese dársele mayor relevancia para ilustrar esta temática.

6 Cfr., artículo 14 de la Ley N 19.638, de 1999.

7 Cfr., Fernández-Coronado González (1995) p. 1409.

8 Cfr., Zabalza Bas (1986) p. 80. 
La tensión descrita en el párrafo anterior, se agrava al constatar que la problemática planteada en este artículo ha sido escasamente resuelta por la jurisprudencia y la doctrinal nacional. Salvo algunos estudios específicos que se recogen en las páginas siguientes, la doctrina laboral chilena no se ha hecho cargo de resolver la exacta configuración jurídica que cabe asignarle al trabajo de religiosos y personas que colaboran con el ideario. Ello nos ha obligado a recurrir a doctrina comparada a objeto de extraer conclusiones generales aplicables al supuesto de hecho que subyace en el presente estudio. En cuanto a la jurisprudencia, la verdad es que solo existen dos fallos relevantes de tribunales superiores de justicia que inciden en la temática planteada: uno dictado por la Excma. Corte Suprema en el año 1956, y otro más reciente (del año 2012) dictado por la Iltma. Corte de Apelaciones de Concepción. Adicionalmente, existen puntuales fallos emitidos sobre la materia por los nuevos juzgados de letras del trabajo así como dictámenes de la Dirección del Trabajo. La falta de un cuerpo sistemático de sentencias judiciales, nos ha obligado a buscar apoyo en criterios jurisprudenciales indirectamente relacionados con el tema de esta investigación, o bien a recurrir a fuentes de análisis más secundarias. Todo lo anterior explica los motivos por los cuales en este artículo se hacen referencias a fallos dictados durante la vigencia del Código de 1931, o a dictámenes administrativos o, también, a fallos que no tienen su origen en tribunales superiores de justicia. En cada uno de estos casos, se ha extraído el criterio dogmático que subyace en la sentencia o resolución administrativa. Lo más complejo, en todo caso, es que esos criterios no son uniformes y en algunos casos el juzgador (o la autoridad administrativa) ha rechazado la petición de laboralizar prestaciones ejecutadas por religiosos o por personas muy cercanas al ideario, bajo el argumento de que se trata de una materia propia del Derecho eclesiástico. En otros supuestos, no obstante, la misma jurisprudencia se ha inclinado por estimar que la entidad religiosa debe sujetarse a los mismos parámetros de cualquier otro sujeto regido por las normas estatales.

Por último, y más allá de algunas referencias particulares que se efectúan más adelante, debemos advertir que el presente artículo no tiene por objeto analizar la vigencia de los derechos fundamentales en el ámbito de la relación laboral. Tampoco tiene estricta relación con los problemas de ciudadanía laboral en el contexto de una entidad religiosa. El punto principal del presente estudio está vinculado a la calificación jurídica de la prestación realizada por religiosos y colaboradores de una organización con ideario religioso definido.

\section{LA AUTONOMÍA ORGANIZATIVA DE LAS ENTIDADES RELIGIOSAS}

Uno de los atributos distintivos de que gozan las entidades religiosas se refiere a su ámbito de autonomía. En términos general, esta autonomía puede ser analizada desde una doble perspectiva. Por una parte, tienen una indisimulable atribución para autoorganizarse mediante la estructura, tanto funcional como territorial, que estimen más idónea para la consecución de sus propios fines institucionales. En esta línea, el Estado debe abstenerse de ejecutar actos que supongan influir en la organización que la propia confesión se ha prefijado 9 . En segundo término, la autonomía de estas entidades les permite gozar de una

9 Cfr., Vicente Cantin (1990) pp. 92 y 93. Véase también Precht Pizarro (2008a) p. 522; y Martin 
facultad de autorreglamentación, en el sentido de que ostentan una capacidad cierta para adoptar las normas necesarias destinadas a regular la vida de la propia institución ${ }^{10}$.

Esta segunda faceta de la autonomía es la que recoge, entre otros aspectos, el artículo 14 de la Ley $N^{\circ} 19.638$ (de 1999), al señalar que las entidades religiosas se rigen también por las normas jurídicas propias de cada una de ellas, las que les permiten introducir sus propias directrices en los requisitos de validez para la adquisición, enajenación y administración de sus bienes. La misma lógica se desprende del artículo 20 de la citada Ley, ya que en dicha norma se reconoce, por parte del Estado, "el ordenamiento, la personalidad jurídica, sea esta de derecho público o de derecho privado, y la plena capacidad de goce y ejercicio de las iglesias, confesiones e instituciones religiosas que los tengan a la fecha de publicación de esta ley, entidades que mantendrán el régimen jurídico que les es propio, sin que ello sea causa de trato desigual entre dichas entidades y las que se constituyan en conformidad a esta ley"11. En el fondo, esto demuestra el reconocimiento de autonomía que el ordenamiento jurídico ha desplegado sobre este tipo de entidades. Esta autonomía no supone, ciertamente, que el respectivo grupo religioso pueda establecer su propio régimen laboral ni menos configurar un ordenamiento jurídico soberano. Ello supondría quebrantar las normas imperativas que el ordenamiento jurídico ha establecido al respecto. Lo que se quiere señalar es que la autonomía jurídicamente reconocida le permite a la Iglesia, confesiones y grupos religiosos organizar su propia estructura, estableciendo derechos y deberes específicos en relación con sus miembros, y respetando lógicamente las normas generales que ha establecido el ordenamiento estatal ${ }^{12}$. De esta forma, en lo que respecta a las prestaciones de servicios, esto no supone la posibilidad de implementar un régimen laboral propio diverso del estatal, sino que solo debe entenderse como la posibilidad de regular aspectos singulares en relación con los miembros de la propia entidad en cuanto desarrollan actividades específicas ${ }^{13}$.

VAlverde (2002a) pp. 275 y ss. En el plano jurisprudencial, véase sentencia de la CORTE DE ApelaCiones DE Concepción de 14 de junio de 2001. RDJ, T. XCVIII (2001), sección quinta, p. 150: "La Ley No 19.638, sobre entidades religiosas de derecho público, obliga al Ministerio de Justicia a inscribir estas entidades en el registro correspondiente con la sola escritura pública en que conste el acta de su constitución y sus estatutos, sin perjuicio que en el plazo que la ley establece al efecto formule por resolución fundada las observaciones del caso, las cuales podrán ser reclamadas con el procedimiento que la ley prevé. Una norma reglamentaria que infrinja requisitos de presentación de una solicitud para ejercer un derecho que la ley no contempla, excede la ley y la vulnera, por lo cual carece de fuerza jurídica que obligue a su cumplimiento. Hay en ello un exceso normativo que significa una violación de la competencia en que ha incurrido su autor".

10 Cfr., Blat Gimeno (1986a) p. 213. Véase también Díez-Picazo (2005) pp. 238 y ss.

11 En igual sentido, cabe mencionar la norma del artículo 547 del Código Civil, cuyo inciso segundo excluye a las Iglesias y comunidades religiosas de las normas del Libro I, Título XXXIII, de dicho texto legal, relativo a las personas jurídicas. En el plano doctrinal, véase además Cortínez Castro (2010) p. 29. A mayor abundamiento, véase sentencia de la Corte Suprema de 5 de enero de 2005. Causa Ingreso Corte N 3640-2004.

12 Cfr., desde una perspectiva general, Calvo Gallego (1995) p. 136; Vicente Cantin (1990) pp. 56 y 57 ., y Zabalza (1986) pp. 162 y 163. En cuanto a la doctrina nacional, véase Precht Pizarro (1989c) pp. 683 y ss. Sobre la necesidad de que toda libertad tenga como contrapartida el bien de la comunidad o de otra persona, véase sentencia de la Corte de Apelaciones de Santiago de 24 de enero de 2007. RDJ T. CIV (2007) p. 636.

13 Cfr., Blat Gimeno (1986a) p. 216. 
Las ideas anteriores, llevadas al ámbito de la regulación laboral, permiten afirmar que, sin perjuicio de su condición de organizaciones con ideario definido, las entidades religiosas se desenvuelven en sus relaciones ordinarias como un empleador más sometido a las reglas generales que el ordenamiento jurídico ha prefigurado. La única excepción, a este respecto, se materializa en el caso de los eclesiásticos y religiosos que prestan servicios para la respectiva organización. Pero en este último caso nos encontramos ante un supuesto diverso, ya que la relación que une a las partes es de una naturaleza diametralmente distinta a aquella que se contempla para cualquier otro empleador que no mantenga con sus trabajadores un vínculo de naturaleza canónica o religiosa. Ese es el criterio que, desde antiguo, ha sostenido la doctrina jurídica ${ }^{14}$.

\section{LA REGULACIÓN DE LA ACTIVIDAD LABORAL EN EL ÁMBITO DE LAS ENTIDADES RELIGIOSAS}

\subsection{El FACtor de “Tendencia” Que PRESENTA la ENTidad REligiosa.}

Como es sabido, las confesiones religiosas se configuran como empleadores de "tendencia ideológica" o simplemente "de tendencia" ("Tendenzbetrieb", del Derecho alemán)15,

14 Cfr., por todos, Alberca de Castro (1999) p. 45; y De Otaduy Guerin (1993c) pp. 61 y 62.

15 Cfr., DÄUbler (1994) p. 427. La legislación alemana, a diferencia del ordenamiento chileno, ha reconocido expresamente a las organizaciones de tendencia ideológica. Sus primeras normas se remontan a la Betriebsrätegesetz del año 1920, cuyo artículo 67 excepcionó a determinadas entidades -como los sindicatos o los partidos políticosde algunos derechos económicos que se consagraban en dicho instrumento legal. Con posterioridad, el parágrafo 118 de la Betriebsverfassung, de 1972, definió a la Tendenzbetriebe como aquella que se encuentra directa y principalmente al servicio de actividades políticas, sindicales, confesionales, caritativas, educativas, científicas y artísticas, o bien tiene una finalidad de información y manifestación del pensamiento. En la actualidad, otros ordenamientos europeos, como es el caso de Suecia o Austria, se han encargado de regular este tipo de figuras. En otros sistemas, por el contrario, no existe una definición legal del concepto de tendencia, así como tampoco una determinación exacta de quién debe ser considerado como titular de una empresa ideológica. Un sector de la doctrina (véase, por todos, Blat Gimeno (1986a) pp. 68, 69 y 79) aboga por un concepto amplio, que involucre a todas aquellas organizaciones que sean expresión del carácter plural de la sociedad, y entre las cuales se encontrarían las confesiones religiosas, los partidos políticos, los sindicatos, las empresas informativas y los centros de enseñanza. Otro sector, por el contrario, sostiene que, en principio, no existirían empresas con características especiales para limitar el ejercicio de derechos fundamentales por parte del trabajador. En palabras de Fernández López (1985) p. 433, no "hay empresa que sea de tendencia por naturaleza”. Más aún: “(...) a un cierto nivel-cargos directivos especialmente- todas las empresas son de tendencia, porque pueden estar interesadas en la adhesión del trabajador a la 'causa' de la empresa, cualquiera que esta sea”. Hay que señalar, no obstante, que excepcionalmente algunos autores partidarios de esta corriente admiten que en casos muy específicos es posible plantear que en las organizaciones con un ideario definido se puedan limitar los derechos de aquellos trabajadores que realizan tareas impregnada de un nítido componente de transmisión del ideario. Por último, en una posición más ecléctica, se ha planteado que solo cabe configurar como empresas de tendencia a aquellas que tienen una especial relevancia constitucional y que institucionalmente expresan dicha ideología [cfr., Aparicio Tovar (1992a) p. 83]. En esta última hipótesis se encontrarían las organizaciones religiosas (conjuntamente con los partidos políticos y las organizaciones sindicales). Con todo, es preciso señalar que parte de la doctrina ha criticado la terminología empresas de tendencia, "ya que, poniendo excesivamente el acento en la organización, es posible que se consoliden injustificadamente áreas exentas de la aplicación de un precepto constitucional. Resulta más adecuado centrar el análisis en la concreta tarea a realizar por el trabajador dentro de la organización” [Rodríguez-Piñero y Bravo-Ferrer y Fernández López (1986) p. 224]. 
cuestión que obliga a que muchas de sus actividades sean desempeñadas única o principalmente por personas coincidentes con el ideario de la organización oferente ${ }^{16}$. Para el empleador, este factor de tendencia representa una mayor ventaja, toda vez que le permite incorporar dentro del contenido obligacional del contrato una actitud congruente, o al menos no confrontacional del trabajador, con el ideario de la entidad religiosa. Si no existiera este elemento de modalización, inevitablemente se generarían tensiones que terminarían dificultando el cumplimiento regular de las finalidades ideológicas de la entidad. Esta característica constituye por cierto una excepción a la regla general, ya que conductas que en cualquier otra empresa serían irrelevantes, en el marco de la entidad religiosa adquieren mayor importancia y obligan a confrontarlas con los deberes de respeto o adhesión al ideario y que son propios del contenido obligacional del contrato de trabajo. Dicho de otra manera, en las organizaciones de tendencia (dentro de las cuales se incorpora a las entidades religiosas) existe una relevancia del interés empresarial en razón de su ideario, cuestión que modaliza el ejercicio de los derechos vinculados con la libertad ideológica del trabajador (y que no sería predicable de otras organizaciones que carecen del factor tendencia) ${ }^{17}$.

En efecto, la mayor parte de los empleadores se desenvuelven bajo la lógica de la neutralidad ideológica. Dicha neutralidad permite separar el ámbito netamente contractual al cual se encuentra obligado el trabajador, de aquel que se refiere al derecho a la libertad religiosa que le corresponde en tanto persona ${ }^{18}$. La neutralidad a la que se hace referencia supone para una empresa, sin ideario religioso, la obligación de tutelar el derecho a la libertad religiosa de su dependiente sin que se pueda indagar sobre sus creencias o convicciones ${ }^{19}$. En este orden de ideas, el reconocimiento de esta libertad se expresa esencialmente en su ámbito negativo; es decir, en el derecho que tiene el trabajador a mantener en su esfe-

16 Cfr., Goñi Sein (1988) pp. 72 y 74.

17 Cfr. Irureta Uriarte (2003) pp. 235 y ss.

18 Cfr., Valdés Dal-Re (2006) pp. 582 y ss. Véase también Fernández Márquez (2007) pp. 75 y ss; y Cavas Martínez (2011) p. 62.

19 En el Derecho chileno, el artículo $2^{\circ}$ del Código del Trabajo prohíbe expresamente que el empleador ejecute distinciones, exclusiones o preferencias basadas en motivos de religión, y que tengan por objeto anular o alterar la igualdad de oportunidades o de trato en el empleo y la ocupación. Más aún, el artículo $5^{\circ}$ del mismo texto legal señala que el poder de dirección del empleador tendrá como límite el ejercicio de los derechos fundamentales del trabajador. Este tipo de prohibiciones se encuentra ampliamente recogida en otros ordenamientos jurídicos. Por ejemplo, en Italia, el artículo $8^{\circ}$ del Statuto del Lavoratori prohíbe que los empleadores investiguen, incluso a través de terceros, las opiniones religiosas de sus trabajadores. En igual sentido, el artículo 122.35 del Code du Travail francés dispone que el Reglamento Interno de las empresas no puede contener disposiciones que afecten negativamente a los trabajadores en sus puestos de trabajo a causa de sus opiniones y confesiones. Este deber de respeto a la libertad religiosa, que se consagra en variados textos laborales europeos, no implica en todo caso que el empleador neutral tenga que acomodarse organizativamente a las convicciones religiosas del trabajador. Distinto es el criterio que se ha seguido en el Derecho norteamericano, el cual ha transitado sobre la base de un deber de acomodación razonable entre la actividad del empleador y las prácticas religiosas del trabajador. Sobre el particular, véase VALDÉs DAL-RE (2006) pp. 593 y ss; y Fernández Márquez (2007) p. 109. Cfr., además, San Millan Novau (1998) pp. 825 y ss. 
ra privada sus respectivas creencias religiosas ${ }^{20}$. Lo anterior encuadra con el reconocimiento legal de la ciudadanía laboral, la cual limita los poderes del empleador ${ }^{21}$.

Como ya se ha dicho, el artículo $5^{\circ}$ del Código del Trabajo establece una barrera al ejercicio del poder de dirección consistente en el respeto de las garantías constitucionales del trabajador. Si bien esta barrera implica un miramiento al contenido esencial de las garantías constitucionales, no necesariamente se traduce en una actitud de fomento o promoción de los derechos fundamentales (cuestión que sí le corresponde a los poderes públicos). En este orden de ideas, y tal como lo ha reconocido la doctrina comparada ${ }^{22}$, los derechos fundamentales no pueden ser vistos como cláusulas ilimitadas de excepción que justifiquen o exoneren al trabajador de las consecuencias derivadas de sus posibles incumplimientos contractuales.

El raciocinio anterior tiene consecuencias directas en el ejercicio de las creencias religiosas. Tradicionalmente, se estimaba que, salvo acuerdo de las partes, las convicciones religiosas del trabajador no entraban dentro del ámbito propio del contrato de trabajo. En este orden de ideas, el empleador podía exigir el cumplimiento del contenido obligacional del contrato siempre y cuando no se vulneraran normas de orden público. En razón de ello, las creencias religiosas del trabajador debían ceder terreno ante los compromisos contractuales libremente asumidos por el trabajador ${ }^{23}$. Si en la práctica, las exigencias religiosas del trabajador generaban una incompatibilidad con las obligaciones laborales de este, entonces se

20 La dimensión positiva de la libertad religiosa (entendida esta como la facultad del trabajador a manifestar las propias creencias, practicarlas y hacerlas públicas, alterando la organización normal de la empresa), es objeto de mayor debate doctrinario. Por una parte, se sostiene que el ejercicio de la libertad religiosa y la ejecución de actos religiosos, debe ser compatible con las obligaciones laborales del trabajador. De esta forma, la libertad religiosa no tendría la fuerza suficiente para matizar las obligaciones contractuales del trabajador ni menos para obligar al empleador a adecuar el contenido obligacional a la práctica religiosa del trabajador. Como señala Fernández Márquez (2007) p. 843, refiriéndose a la libertad religiosa del trabajador: "No comprende el derecho a una afirmación religiosa en sentido fuerte - un derecho a exteriorizar y cumplir todo lo que la propia religión prescribe-, que sea incompatible con las obligaciones profesionales típicas del trabajador. Quiere ello decir que en el ámbito del contrato de trabajo la concurrencia entre la libertad religiosa del trabajador y el derecho del empleador a explotar eficientemente la empresa (...) se resuelve (...) en términos de sacrificio de la libertad religiosa”. En igual sentido, Martin Valverde (2008b) p. 283: “(...) tales creencias (del trabajador) no pueden imponer una novación o modificación unilateral del contrato de trabajo, eximiendo de una obligación de trabajar asumida voluntariamente"; y Cavas Martínez (2011) p. 63: “(...) la empresa se considera un ámbito 'laico', que no tiene por qué alterar su funcionamiento para adaptarse a los hábitos religiosos de los trabajadores”. En contraposición a este criterio, se ha ido abriendo paso una serie de argumentaciones tendientes a matizar el derecho del empleador en contraposición a la libertad religiosa del trabajador en su sentido positivo. Básicamente, se sostiene que si la creencia profesada por el trabajador constituye una verdadera religión, si esta supone la imposición de "contenidos imperativos", entonces resulta excesivo reconducir el análisis de esta contraposición de derechos a una cuestión meramente contractual. De alguna manera, se termina reconociendo que el ejercicio de la libertad religiosa termina afectando cuestiones propias del orden público. Sobre el particular, véase Fernández Márquez (2007) pp. 89 y ss.

21 Cfr. Ugarte Cataldo (2007) pp. 49 y ss.

22 Véase Calvo Gallego (1995) p. 175.

23 Véase Gil y Gil (2003) p. 235: "Si el trabajador pretende que el empresario las tome en consideración, ha de informar a este al negociar el contrato. De no hacerlo así, el trabajador no puede invocarlas para suspender el trabajo (...)". 
estimaba que el trabajador debía cooperar con el empleador sin forzar un cambio relevante del contenido obligacional del contrato.

Sin embargo, y en virtud de una fuerte influencia del Derecho norteamericano, la posición anterior fue objeto de inevitables matices. En efecto, y aun persistiendo una incompatibilidad entre el ejercicio de la libertad religiosa y el pacto laboral voluntariamente celebrado por el trabajador, el empleador se encuentra en la necesidad de realizar una acomodación razonable del sistema organizativo partiendo de la base que el trabajador no está obligado a efectuar tareas contrarias a sus creencias religiosas sin que antes el empleador le ofrezca una solución adecuada. Lo dicho no significa que el titular de la actividad productiva tenga que soportar un gravamen excesivo; simplemente, supone la realización de una propuesta razonable de acomodación. Desde luego, la acomodación razonable solo puede ser resuelta en función de las circunstancias concretas de cada caso. Con todo, si dicha propuesta de acomodación importa, en definitiva, un sacrificio del trabajador, entonces sobre el empleador pesa la necesidad de justificar su procedencia.

La justificación de una conducta eventualmente limitativa se encuentra ligada al principio de proporcionalidad. Como es ampliamente sabido, este principio supone el cumplimiento de tres requisitos básicos: un juicio de idoneidad, en el sentido que la medida adoptada por el empleador sea susceptible de conseguir el objetivo propuesto; un juicio de necesidad, el cual parte de la base que la medida es necesaria y que no existe otra alternativa más atenuada para la consecución de un propósito de igual eficacia; y un juicio de proporcionalidad propiamente tal: la medida es ponderada y equilibrada pues de ella se derivan consecuencias más beneficiosas para el interés general ${ }^{24}$.

\subsection{LA INFLUENCIA DE LA DIMENSIÓN RELIGIOSA EN EL TRABAJO DEL COLABORADOR.}

Aun cuando la regla general es que las organizaciones empresariales ejerciten una neutralidad ideológica con respecto a sus trabajadores, las organizaciones con ideario tendencialmente definido (y dentro de las cuales se encuentran las entidades religiosas) logran exceptuarse de este criterio. Ellas se caracterizan, fundamentalmente, por el hecho de ser capaces de incorporar, dentro del contenido obligacional del contrato de trabajo, la orientación ideológica de la que son institucionalmente expresivas ${ }^{25}$.

\footnotetext{
24 Véase por todos CaAmaño Rojo (2006) p. 41.

25 Véase por todos Irureta Uriarte (2003) p. 238; y Martin Valverde (2008b) p. 296. Con todo, la jurisprudencia ha tendido a matizar la influencia del ideario del empleador sobre el contrato de trabajo. Así, por ejemplo, en sentencia de 18 de marzo de 2010 la Corte Suprema concluyó que la circunstancia de que el empleador fuese una congregación religiosa no podía constituir en sí misma un antecedente suficiente para determinar la gravedad del hecho "ni es relevante que se haya estipulado en el contrato que el trabajador se obligara en términos más rigurosos" (Causa Ingreso Corte Suprema N³22-2010). El caso decía relación con una trabajadora que desempeñaba labores de Inspectora General de un colegio cuya titularidad le correspondía a una congregación. En dicho rol, emitió un certificado dando cuenta de su situación contractual y de la fecha de duración de la misma, sin que estuviese autorizada para ello. Esta acción la ejecutó sin conocimiento de la empleadora, quien se enteró del hecho a raíz de una consulta formulada por una entidad bancaria (Banco Ripley). Más aún, en el proceso la congregación alegó que la emisión de certificados era una atribución propia de la directora del establecimiento, que el documento se suscribió con otra firma (utilizando el nombre de “inspectoría”), y que el hecho en cuestión suponía afectar la imagen del establecimiento. El tribunal de primera instancia (en un criterio que confirmó la Corte de Apelaciones) acogió los argumentos de la congregación
} 
Desde esta perspectiva, las organizaciones religiosas se vinculan con las personas que le prestan servicios fundadas principalmente en el ideario que profesan. Tan importante es este ideario que, sin él, la entidad religiosa perdería su propia esencia ${ }^{26}$. Dentro de este esquema, las entidades religiosas mantienen una dualidad de vínculos que se expresan fundamentalmente en la existencia del trabajo efectuado por los propios religiosos o por laicos al servicio de las confesiones religiosas ${ }^{27}$.

demandada agregando que "la función desempeñada por la actora era de Inspectora General, cuyo contrato en su cláusula segunda señala que la actora se compromete a respetar y cumplir los principios y valores propios del establecimiento educacional". No obstante, la Corte Suprema anuló la sentencia y estimó que el carácter de congregación religiosa que ostentaba el empleador no era suficiente para calificar en términos más rigurosos la conducta de la trabajadora. Una orientación jurisprudencial similar, aunque en un caso referido a la adhesión política, puede consultarse en la sentencia de la Corte de Apelaciones de Santiago de 3 de octubre de 1995. RDJ T. XCII, sección tercera (1995) p. 164: "No es óbice para estimar configurada una relación laboral la circunstancia de que los servicios se presten con ocasión de una campaña política si en la prestación de esos servicios concurren las exigencias previstas por la ley para presumir la existencia de un contrato de trabajo".

26 Con todo, el concepto de empresa ideológica y la amplitud de su actuación no ha sido pacífico. Una parte de la doctrina (véase, Aparicio Tovar (1980b) p. 294. Véase, también, del mismo autor, Aparicio Tovar (1992a) p. 90) ha planteado una posición restringida en torno al alcance que debe otorgárseles a las instituciones dependientes de una confesión religiosa, ya que se estaría exorbitando el concepto de organización de tendencia mediante la incorporación de entes gestionados por las organizaciones originarias o creadoras de la propia ideología. Para fundamentar este criterio, la misma doctrina ha estimado como un absurdo calificar de ideológica a una compañía naviera fundada por una congregación religiosa, aun cuando el móvil de la creación no sea solo el mero afán de lucro sino que también el de servir a la misión que a sí misma se ha dado dicha entidad. Una posición similar puede observarse en Calvo Gallego (1995) p. 79: "no podrán ser consideradas organizaciones de tendencia aquellas instituciones u organismos que, constituidos al amparo de la general capacidad de obrar reconocida a estos grupos, carezcan de cualquier finalidad o motivación ideológica. (...) A través de estos entes no se ejercita ningún derecho fundamental de contenido ideológico, ni se transmite una concepción ideal del mundo". En contra de este criterio, se ha argumentado que el carácter religioso de las confesiones abarcaría, incluso, a los entes gestionados por estas. Los fundamentos de esta conclusión descansan en dos aspectos: a) Existe una dependencia o vinculación más o menos directa entre el ente y la respectiva confesión; y b) Existe un claro fin religioso, el cual debe abarcar dentro de sí a todas aquellas actividades que aun cuando no sean eminentemente culturales o espirituales igual se encuentran conexas al fin que profesa la confesión. Esta concepción más amplia ha sido defendida, entre otros, por Moreno Botella (1987) p. 535, quien se opone a una concepción restrictiva ya que "no parece tener en cuenta que el elemento ideológico, decisivo para configurar a una organización como de 'tendencia', puede ser más importante de cara al exterior, en las organizaciones instrumentales de las que se sirve la organización originaria para dar a conocer su específico programa, que en la propia organización catalogada como de 'tendencia”. En un sentido similar, véase, Vicente Cantin (1990) p. 121: "Lo que no puede admitirse (...) (es) que el amplio campo de la beneficencia y de la asistencia no sea una actividad religiosa, que no forme parte del objeto del derecho de libertad religiosa, exigiendo la total secularización de la beneficencia y de la asistencia"; y, aun cuando se refiere a la tarea del trabajador, Rodríguez-Piñero y Bravo Ferrer y Fernández López (1986) p. 225: "es posible que existan 'tareas de tendencia' también en organizaciones en que, siendo esencial en ellas la difusión ideológica, dicha finalidad se persiga a través de medios lucrativos, ya que este fin básico permite caracterizar a la empresa frente a cualquier otra empresa comercial”. A lo anterior habría que agregar que la intensidad del ideario que plantea la organización parece imbuir la totalidad de sus actividades, ya que el fin inmediato y principal es el de propagar la doctrina en la realidad concreta. Y para ello podrán utilizarse una multiplicidad de mecanismos instrumentales. Lo que no puede perderse de vista, en todo caso, es que la autonomía de estas entidades solo puede extenderse a los ámbitos propios de la religión o de la estructura organizativa (cfr., Calvo Gallego (1995) p. 136).

27 Véase, Borrajo Dacruz (1988) pp. 329 y 330. 
En el primer caso, ciertamente que las organizaciones religiosas no se comportan como un empleador al estilo de lo preceptuado en la legislación laboral. Allí no ha existido intención de celebrar un verdadero contrato de trabajo y la mayor parte de las actividades que realicen sus miembros deberán entenderse como una manifestación del vínculo religioso que se mantiene con la confesión, en el entendido de que el sujeto obedece órdenes de un superior eclesiástico y no de un empleador ${ }^{28}$. Los argumentos para fundar esta conclusión han transitado, indistintamente, por la tesis de que en este tipo de relaciones se produciría un vínculo asociativo, o bien un trabajo por cuenta propia análogo al familiar, situaciones ambas que se encuentran excluidas del ámbito de la legislación laboral ${ }^{29}$. A lo anterior habría que agregar que aun cuando la entidad religiosa otorga en muchos casos una retribución mensual básica, ella no constituye remuneración para ningún efecto, ya que simplemente se le están sufragando al miembro de la entidad los gastos indispensables para el ejercicio de las actividades que le son propias en razón de su pertenencia ${ }^{30}$.

$\mathrm{Al}$ no encontrarse sometida dicha actividad por el imperio de la legislación laboral, entonces el receptor de los servicios no puede ser configurado como un verdadero emplea-

28 Cfr., Borrajo Dacruz (1988) p. 330; Del Peso y Calvo (1966) p. 275. Véase, también, Aznar Gil (1986) p. 435: "La relación que liga al sacerdote con la diócesis y con la Iglesia misma no está, no puede estar, basada en una relación contractual o disciplinaria, aunque esta última exista. La relación sacerdoteIglesia, desde el punto de vista jurídico, está basada en una 'afectio' vocacional y espiritual. El sacerdote no es un profesional al servicio de la Iglesia, no es un trabajador por cuenta ajena. El sacerdote es un trabajador al servicio de sus propias creencias y vocación"; y BASDEVANT-GAUDEMET (1996) p. 136: "No puede hablarse de contrato de trabajo entre un clérigo y su superior jerárquico; (...). Las relaciones son de otro orden”. En el plano jurisprudencial, véase sentencia de la Corte Suprema de 5 de enero de 2005. Causa Ingreso Corte $\mathrm{N}^{\circ}$ 3640-2004: “37: (...) si la 'organización interna' de la iglesia se rige, como lo estipula el artículo 20 de la ley 19.638 por el 'régimen jurídico que le es propio', entonces la relación entre sus distintos integrantes está precisamente regulada por ese ordenamiento propio el cual, por consiguiente, 'no tiene caracteres civiles' como erradamente concluye el fallador". Y se agrega: “ $50^{\circ}$ ) Que, por otra parte, la potestad que detenta el obispo sobre los clérigos de su diócesis, entendida como aquí se lo hace, tampoco puede ser homologada a un vínculo de subordinación y dependencia como el que el artículo 2322 (del Código Civil) presupone que existiría entre los amos y sus criados o sirvientes en el ejercicio de sus respectivas funciones, el cual, a la luz de una interpretación progresiva puede hoy considerarse equivalente al que vincula al empleador y sus empleados. Esta última relación, en efecto, implica la existencia de un vínculo contractual del cual derivan derechos y obligaciones recíprocas cuyo cumplimiento es susceptible incluso de ser reclamado judicialmente, cosa que nada tiene que ver con el que une al obispo con sus sacerdotes diocesanos, el cual se encuentra configurado como una 'comunión', es decir, como participación en un 'servicio común'”. Una posición contraria a este criterio jurisprudencial puede consultarse en Varas Braun (2005) pp. 241 y ss.

29 Cfr., Blat Gimeno (1990b) p. 172; y Calvo Gallego (1995) p. 139.

30 Cfr., Aznar Gil (1986) pp. 419, 423, 435 y 437. En igual sentido, Martin Valverde (2002a) p. 49. En relación con la inexistencia de un deber retributivo, de carácter jurídico-laboral, por parte del empleador religioso, véase, por todos, De Otaduy Guerin (1993c) p. 37: "La situación de los clérigos frente a las estructuras eclesiásticas es muy otra. El servicio que desempeñan responde a razones enteramente altruistas y se inspiran en criterios de gratuidad. La formalización jurídica de esa relación difícilmente puede llevarse a cabo - sin producir su radical desnaturalización- mediante la aplicación de los principios del sinalagma contractual”. Cfr., además, Dictamen $N^{\circ}$ 0058/001, de 7 de enero de 2010, de la Dirección del Trabajo, el cual concluye que "el trabajo gratuito es aquel que se presta por regla generalísima, en forma ocasional y discontinua en el tiempo, en forma voluntaria por parte del prestador de los servicios y sin perseguir una remuneración a cambio, encontrando su justificación en razones tales como la solidaridad, la buena vecindad, el agradecimiento, la familiaridad u otra finalidad lícita. Así también, el móvil de la prestación desinteresada puede también girar en torno a empresas ideológicas, partidos, sindicatos, agrupaciones artísticas, organizaciones no gubernamentales”. 
dor. Lo que se distingue en este caso, por tanto, no es el tipo de servicio ejecutado, sino la naturaleza extralaboral del vínculo. Este criterio, ampliamente aceptado por la doctrina (al menos comparada) ${ }^{31}$, viene a suponer que en las relaciones existentes entre un miembro de

31 Véase, entre otros, Alberca de Castro (1999) p. 46; Blat Gimeno (1986a) pp. 222 y 223; Borrajo Dacruz (1988) pp. 330, 336 y 340; Calvo Gallego (1995) pp. 136 y 137; De Otaduy Guerin (1993c) pp. 24 y siguientes; Del Peso y Calvo (1966) pp. 275 y 276; Fernández-Coronado González (1995) p. 1411; Moreno Botella (1987) p. 543; Valdés Dal-Re (2006) p. 568; y Vicente Cantin (1990) pp. 93 y 98. Véase, además, Alonso Olea y Montoya Melgar (1995) pp. 168 y siguientes, quienes analizan un caso de la jurisprudencia española en el cual se estimó que entre la demandante y la Congregación no existía relación contractual de ninguna clase, sino la relación canónica derivada de la profesión religiosa. Y agregan los autores en p. 169: "la relación entre religiosa y Congregación careció de naturaleza laboral. La religiosa no mantenía dos vínculos superpuestos con su comunidad -uno religioso, otro contractual-, sino que su prestación como profesora era parte integrante de su oficio religioso". En el nuevo sistema procesal laboral imperante en Chile, ya es posible encontrar sentencias en esta misma línea. Por ejemplo, el fallo de 26 de enero de 2011, dictado por el Segundo Juzgado de Letras del Trabajo de Santiago, concluye que "teniendo presente que la demandante ha ejercido funciones de docencia en colegios de la demandada, no en razón de un contrato de trabajo, sino que del voto de obediencia que profesó en su calidad de religiosa, voto libremente asumido por esta, en virtud del cual se comprometió a llevar una vida acorde con las directrices de la congregación, lo que importaba la realización de distintas tareas en colegios, parroquias, conventos u otros de la demandada, no siendo posible que las partes estén obligadas por dos vínculos que importen obediencia y subordinación a la vez, el Tribunal estima que dichos votos son incompatibles con la configuración de un contrato de trabajo, por lo que en consecuencia, se acoge la excepción de incompetencia interpuesta por la demandante" (Causa RIT N ${ }^{\circ}$ O-37352010). En igual sentido, puede consultarse la sentencia del mismo Segundo Juzgado de Letras del Trabajo de Santiago, de 12 de agosto de 2011. En dicha causa, el demandante alegaba que entre la congregación religiosa y él había existido un doble vínculo religioso y laboral. Ante ello, la congregación demandada entabló excepción de incompetencia fundada en que el vínculo existente entre las partes era de tipo religioso regido por las normas del derecho canónico y no por el Derecho del Trabajo. A juicio del tribunal, si bien en principio no existiría obstáculo para que las partes pudiesen tener en paralelo dos vínculos distintos, el problema radica en como distinguir en este caso aquellas órdenes que eventualmente se dan en razón del vínculo de subordinación con aquellas órdenes que se dan en virtud del voto de obediencia (más aun "cuando la congregación demandada se dedica a las labores educacionales y por tanto dentro de las obligaciones que asumen los religiosos en virtud del voto de obediencia se encuentra la de servir a la congregación ya sea prestando servicios educacionales o en algún otra labor distinta"). El mismo fallo indica que en la calificación del vínculo se presentarían problemas relacionados con la remuneración: "en este caso también es difícil establecer la existencia de una remuneración más allá que para efectos formales o a fin de beneficiar a los religiosos con la posibilidad de acceder a una jubilación o a prestaciones médicas la demandada pague cotizaciones previsionales y de salud". Todo lo anterior llevó a que el tribunal concluyera que en este caso las obligaciones desempeñadas por el religioso en los colegios de la congregación demandada "se han cumplido no en virtud de un contrato de trabajo, más allá de los documentos que se han exhibido en esta audiencia y de las explicaciones que ha dado la demandada respecto de por qué formalmente tenían la obligación de mantener un contrato de trabajo no solo respecto del personal laico si no que también respecto del personal religioso". A mayor abundamiento, el tribunal estimó "que estas obligaciones se han cumplido en virtud del voto de obediencia contraído por el actor, vínculo que está regulado por el derecho canónico y que asimismo regula las relaciones entre una congregación y sus religiosos ya sean sacerdotes, postulantes, novicios y diáconos como es el caso del demandante, estimando como se dijo que no resulta posible separar ese vínculo del vínculo laboral y en ese sentido es incompatible a juicio de este tribunal la existencia de un vínculo laboral y un vínculo religioso a la vez" (sentencia del Segundo Juzgado de Letras del Trabajo de Santiago de 12 de agosto de 2011. Causa RIT No T-239-2011). Sin perjuicio de lo anterior, existe jurisprudencia laboral contraria a lo señalado con anterioridad. En efecto, la sentencia de la Corte de Apelaciones de Concepción de 13 de abril de 2012 (Causa Ingreso Corte $\mathrm{N}^{\circ}$ 42-2012) ha concluido, ante un caso similar, que en la especie se produciría una relación laboral entre el miembro de la congregación y la entidad religiosa: " 4 o.- Que, el sentenciador, no obstante dar por establecido que el actor desempeñó funciones de rector del Liceo San Pedro Nolasco, bajo subordinación de sus autoridades religiosas, que se le hicieron cotizaciones 
la entidad religiosa y su respectiva organización, se verifica un vínculo de naturaleza extralaboral regido por las normas internas de cada confesión, las cuales en todo caso deberán respetar los derechos fundamentales de aquel ${ }^{32}$.

La situación es diametralmente distinta, como es lógico, si el miembro de la entidad religiosa presta servicios para un tercero fuera del régimen de su comunidad. Si dichos ser-

previsionales y liquidación de sueldo, egresos que se registraron como remuneración en los gastos del Colegio, pero que por no percibir el estipendio el actor, sino recibirlo la Orden religiosa de acuerdo al voto de pobreza, no reconoció la existencia del vínculo laboral, sosteniendo que dicha relación se regía por las normas de la Congregación. Esta decisión infringió disposiciones legales que se pasan a detallar. En efecto, en esta causa se discutió la existencia de una relación laboral y la justificación de su despido entre un sacerdote que desempeñó labores de rector del Liceo San Pedro Nolasco, asunto de índole laboral, que debió ser dirimido conforme a las normas del Código del Trabajo y sus leyes complementarias, como lo dispone el artículo $1^{\circ}$ del citado cuerpo legal. Cabe agregar que la Orden religiosa como la Fundación a cargo de la administración del Colegio, no aparece excluida de dicha competencia, al tenor de la misma disposición legal citada. Es más, la fundación Liceo San Pedro Nolasco de Concepción no ha acreditado ser un organismo religioso canónico, de manera que se trata de una fundación, que se rige por el Título XXXIII del Libro I del Código Civil y por ende, sujeto de derechos y obligaciones conforme al derecho común. Finalmente, esta materia no se trata de una relación entre una Orden religiosa y su personal consagrado, sino de relaciones laborales ordinarias. De igual manera, infringió la sentencia lo dispuesto en los artículos 3 letras a) y b), 4, 5, 7, 8 y 9 del Código del Trabajo, al no dar correcta aplicación a lo que se entiende por trabajador, empleador, representante del empleador, no reconoció la irrenunciabilidad de los derechos establecidos por las leyes laborales, el concepto de contrato de trabajo y sus características. Lo anterior se desprende del error de la sentencia de inaplicar la legislación laboral chilena para determinar la existencia de la relación laboral entre las partes. Además, el hecho que la remuneración no fuera percibida por el trabajador (el actor) sino por la Congregación a que pertenecía, no afecta la esencia de la relación laboral, que es la existencia de una prestación de servicios personales bajo subordinación y dependencia del empleador, quien le debe pagar una remuneración, lo que ocurrió en la especie. La circunstancia de aceptar el trabajador que el sueldo sea percibido por la Orden religiosa corresponde a su decisión privada, pero no le resta validez al contrato de trabajo". El fallo en cuestión dio por establecido que no existía discusión que entre el actor y la Orden Mercedaria hubo una relación de orden religiosa, "de sacerdote con su Congregación, con la cual hizo 'voto de pobreza', lo que se rige por el derecho canónico". No obstante, a juicio de la sentencia, cosa distinta era la relación material de prestación de servicios, tanto a la misma Orden religiosa y luego a su sucesora la Fundación, como rector de Colegio. Según la Corte, el hecho que el demandante tuviera "voto de pobreza", no obsta para tener un vínculo laboral con la Congregación, "pues este compromiso de orden espiritual, corresponde a su vida privada".

32 Véase, en la jurisprudencia nacional, sentencia de la Corte Suprema de 22 de junio de 1956. Repertorio de Legislación y Jurisprudencia Chilenas. Código del Trabajo (1958) p. 7: "No existe contrato de trabajo si consta que los servicios como profesor se prestaron en calidad de miembro de una congregación religiosa que desarrolla sus actividades especialmente en el campo de la enseñanza”. Si bien este fallo fue dictado bajo la vigencia del Código del Trabajo de 1931, lo cierto es que era la única sentencia judicial relevante sobre esta materia que se hubiese emitido hasta antes de la entrada en rigor del nuevo sistema procesal laboral de la Ley $N^{\circ}$ 20.087. Desde luego, la doctrina que subyace en este fallo no ha perdido actualidad y ha sido invocada como fundamento de un específico recurso de unificación de jurisprudencia en el año 2012. Criterios similares pueden observarse en el Dictamen N 3599 de la Dirección del Trabajo, de 16 de mayo de 1991: "No se aplica la legislación laboral contenida en el Código del Trabajo y leyes complementarias a los pastores de iglesia constituidas como corporaciones de derecho privado. La labor de ellas emana directamente de la religión que profesan, es decir, es una labor de difusión de una fe cuya existencia, permanencia o término, va más allá de circunstancias meramente contractuales, ya que la ejecución de sus servicios no se realiza en beneficio de una persona natural o jurídica determinada”. Repertorio de Legislación y Jurisprudencia Chilenas. Código del Trabajo y Leyes Complementarias (2002) p. 12. La misma doctrina se recoge en el Dictamen $\mathrm{N}^{\circ}$ 649/22, de 9 de febrero de 2005. A mayor abundamiento, véase Dictamen $\mathrm{N}^{\circ}$ 1036, de 19 de abril de 1979, Dictamen $\mathrm{N}^{\circ} 11.442$, de 4 de octubre de 1985, y Dictamen $N^{\circ} 12.379$, de 1 de julio de 1998, de la Superintendencia de Seguridad Social, recogidos en Klenner Gutiérrez (2007) pp. 216 y ss. 
vicios se encuentran alejados de la práctica del culto o de la asistencia religioso-pastoral ${ }^{33}$, entonces no cabe duda que el receptor de esos servicios asumirá la condición de empleador de conformidad con las normas generales del Código del Trabajo ya que el estatus religioso no tiene por qué alterar la naturaleza del vínculo. Tanto es así, que la Iglesia o la respectiva confesión no tiene ninguna posibilidad de control o regulación sobre la remuneración obtenida por el clérigo en el ejercicio de un trabajo o profesión civil. Por el contrario, si lo que se verifican son prestaciones caracterizadas por su tipología religiosa, habrá que concluir que la normativa aplicable será aquella que rige la respectiva actividad. Ese es el caso que sucede, por ejemplo, en la asistencia religioso-pastoral que se presta a los miembros de las Fuerzas Armadas o a las personas internados en establecimientos penitenciarios, en que existen normas especiales para configurar esos vínculos ${ }^{34}$.

Con todo, si el religioso llegase a abandonar la confesión debido, por ejemplo, a un proceso de secularización, la posterior continuidad en la prestación de servicios convierten a la respectiva entidad en un empleador de conformidad con las normas de la legislación estatal. Y lo anterior es de toda racionalidad, ya que en esta hipótesis se ha producido una mutación del vínculo religioso por uno de carácter laboral ${ }^{35}$. En definitiva, en estos casos debemos admitir una laboralidad en el vínculo cada vez que el religioso continúa prestando servicios con posterioridad al indulto de exclaustración y secularización ${ }^{36}$.

Con respecto a la situación que se verifica en el caso de prestaciones efectuadas por laicos, la conclusión generalizada tiene que enfocarse por la tesis de que las organizaciones religiosas se comportan como un empleador laboral más, sin perjuicio de las singularidades propias que se derivan de la naturaleza jurídica de este empleador ${ }^{37}$. Si bien con anteriori-

33 Cfr. Klenner Gutiérrez (2007) p. 275.

34 Sobre el particular, véase, a nivel doctrinal y entre otros, Alberca de Castro, (1999) p. 436; Aznar Gil (1986) pp. 444 y 466; Blat Gimeno (1986a) pp. 230 y siguientes; Blat Gimeno (1990b) p. 172; Borrajo Dacruz (1988) p. 330; Calvo Gallego (1995) p. 140; De Otaduy Guerin (1993c) pp. 63, 66, 76, 96 y 103; Del Peso y Calvo (1966) p. 281; y Moreno Botella (1987) p. 543. Distinta es la situación que se produce, en todo caso, en el ordenamiento alemán. Como explica Zabalza Bas (1986) pp. 158 y 159, uno de los derechos más relevantes de las organizaciones religiosas alemanas es la posibilidad de regular las relaciones jurídico-laborales con sus colaboradores fuera del ámbito jurídico del Derecho del Trabajo. Lo que ocurre es que las confesiones religiosas en Alemania tienen la posibilidad de que la persona que es investida con un cargo eclesiástico adquiera el estatus de funcionario. "Se trata aquí de un estatus de funcionario público eclesial y no estatal, lo cual significa que no pertenece a la administración pública del Estado, como ocurriría si de una 'auténtica' corporación de derecho público se tratase, sino que forma parte de la administración pública de la comunidad religiosa en cuestión. Sin embargo, este estatus de funcionario público eclesial, confiere a su titular una posición jurídico-laboral equiparable a la de cualquier funcionario público estatal”. De esta forma, la confesión religiosa ostenta un Dienstherrenfähigkei que la convierte en un empleador de funcionarios, cuestión que puede ser aplicado tanto a los clérigos como a los laicos. Esta alternativa, que supone apartarse de la normativa jurídico-pública del Derecho del Trabajo, refleja a fin de cuentas la capacidad de estas organizaciones para ordenar y administrar sus asuntos propios de forma independiente. Y esta conclusión no se opone, al menos en el ordenamiento alemán, a que existan prestaciones estatales destinadas a la retribución y cuidado de los religiosos o funcionarios eclesiales.

35 Cfr. Martin Valverde (2008b) pp. 292 y ss.

36 Sobre el particular, véase Borrajo Dacruz (1988) p. 340. Véase también Klenner Gutiérrez (2007) p. 108.

37 Una de esas singularidades se verifica, precisamente, por la existencia de las denominadas cláusulas de salvaguarda de la identidad o del carácter propio de la respectiva confesión. No cabe duda, en este sentido, que las respectivas Iglesias, Confesiones y grupos religiosos tienen una identidad y especificidad que les lleva 
dad existía la tendencia a distinguir entre trabajos relacionados con la práctica del culto y aquellos que se configuraban como servicios profesionales ordinarios, lo cierto es que en la actualidad esa clasificación es irrelevante para efectos de atribuirle la condición de empleador a la organización receptora de los servicios. Siempre que se verifique una prestación de conformidad con el artículo $7^{\circ}$ del Código del Trabajo, la organización religiosa respectiva tendrá que ser catalogada como empleador para efectos laborales ${ }^{38}$. Por el contrario, la organización religiosa no deberá ser configurada como empleadora si los servicios que presta el laico tienen su origen en una colaboración benévola, de altruismo ${ }^{39}$, o en actos episódicos, ocasionales o aislados, toda vez que allí no se produce la hipótesis planteada por la legislación laboral ${ }^{40}$. Tanto es así que el propio Código Canónico de 1983 ha tenido que señalar que los laicos que, de modo permanente o temporal, se dediquen a un servicio especial de la Iglesia tienen derecho a una conveniente retribución que responda a su condición, "de acuerdo también con las prescripciones del derecho civil" 41 .

Sin perjuicio de lo anterior, la naturaleza de las labores resulta relevante cuando las convicciones son esenciales para el desempeño del cargo o función contratado. De cierta manera la propia misión de la entidad religiosa puede verse afectada si se produce una desafección del ideario, cuestión que obliga a identificar muy rigurosamente el contenido obligacional del vínculo y la adecuada ponderación de los límites al ejercicio del derecho a

a constituirse y organizarse de acuerdo con sus dogmas y su moral (cfr., Vicente Cantin [1990] p. 92). Esto permite que los empleadores religiosos puedan hacer prevalecer su posición en caso de producirse un conflicto con las personas que les prestan servicios, aun cuando ello no podrá suponer en caso alguno un despojo de las garantías establecidas por la legislación estatal. Esta materia ha sido especialmente debatida en relación con el derecho de dirección que tienen los titulares de centros docentes privados, en el entendido de que en estos concurre un ideal que se refleja en la formación global del individuo de acuerdo a una determinada concepción del mundo. El fundamento de este ideario, en el caso de los centros docentes, se encuentra en el propio artículo $19 \mathrm{~N}^{\circ} 11 \mathrm{CPR}$ ya que esta norma forma parte de la libertad de creación de centros, en cuanto equivale a la posibilidad de dotar a estos de un carácter u orientación propios. En todo caso, y en lo que respecta a los centros concertados, no cabe duda de que el elemento religioso cumple un especial papel en el ámbito de las relaciones de trabajo que se mantengan, aceptándose determinadas excepciones al régimen ordinario. En esta perspectiva, el ejercicio de los derechos y libertades del docente en el ámbito de un centro religioso en que presta servicios se ve modalizado (y en algunos casos limitado) por el derecho que tiene el titular para definir su carácter propio. Sobre el particular, véase, a nivel doctrinal y entre otros, BAYLOS GRAU (1980) pp. 263 y siguientes; De Otaduy Guerin (1991 b, pp. 399 y siguientes; del mismo autor, De Otaduy Guerin (1986a) pp. 329 y 330; Maldonado Montoya (2012) pp. 167 y ss; Moreno Anton (1989) pp. 163 y siguientes; Moreno Botella (1987) pp. 529 y siguientes; Moro Almaraz (1986) pp. 404 y 405; Precht Pizarro (2008a) p. 523; Rodríguez-Piñero y Bravo-Ferrer y Fernández López (1986) pp. 227 y 228 ; y Rojas Rivero (1991a) pp. 195 y siguientes. En el plano jurisprudencial véase también sentencia de la Corte de Apelaciones de Valdivia de 5 de mayo de 2005. Causa Ingreso Corte $\mathrm{N}^{\circ} 2303-2005$.

38 Cfr. Cortínez Castro, S.J. (2010) p. 35.

39 Cfr., Martin Valverde (2002a) pp. 47 y ss. Véase también Alberca de Castro (1999) p. 44.

40 Eventualmente, en el derecho comparado, se ha estimado que los servicios prestados por una cocinera de una residencia de propiedad de una organización religiosa sí dan lugar a una relación laboral de carácter especial. En esta perspectiva, véase una situación de hecho similar, con la diferencia de que el empleador era una religiosa célibe, en Fontes Bastos (1989) pp. 713 y siguientes.

41 Véase, al respecto, canon 231. El canon 1286 señala, por su parte, que los administradores de bienes en los contratos de trabajo y conforme a los principios que enseña la Iglesia, han de observar cuidadosamente las leyes civiles en materia laboral y social, debiendo pagar un salario justo y honesto al personal contratado. Véase también Olmos Ortega (2001) pp. 565 y ss. 
la libertad religiosa que también ostenta el trabajador ${ }^{42}$. No hay que olvidar que el carácter tendencial del empleador religioso lo configura como una entidad orientada a la consecución de valores, que supera el mero interés de empresa ${ }^{43}$, y que de alguna forma realza el deber de sintonización del trabajador con el ideario del empleador ${ }^{44}$.

Cabe tener presente, en todo caso, que el contenido obligacional del trabajo desempeñado por el laico se ve de cierta manera teñido por el ideario de la organización religiosa la cual se constituye precisamente para propagar su imago mundi. En este contexto, en el ejercicio de la prestación, el colaborador laico no puede olvidar la identidad y el carácter propio de la entidad religiosa con la cual ha contratado cuestión que se traduce en una conducta al menos no confrontacional con el ideario ${ }^{45}$. En caso contrario, el empleador religioso se encontrará facultado para extinguir el contrato de trabajo por incumplimiento grave sobreviniente del trabajador para el puesto de trabajo que desempeña ${ }^{46}$. Como se ha señalado doctrinariamente, comportamientos que en otra empresa serían considerados irrelevantes adquieren en las organizaciones religiosas una notoriedad de tal importancia que justifican la extinción del vínculo ${ }^{47}$. Esa sola circunstancia viene a reflejar la distinta configuración que presentan este tipo de entidades con respecto al régimen ordinario que regula la legislación estatal.

El análisis de esta materia parte de la base que los trabajadores que prestan servicios para una entidad religiosa son, de alguna manera, colaboradores en la realización del ideario de su empleador. Pero ello no impide la distinción, al menos doctrinariamente, entre trabajadores que prestan servicios completamente irrelevantes para el cumplimiento del ideario (v. gr., funciones meramente administrativas), y aquellos que trabajan directamente conectados con la propagación del imago mundi que pregona la entidad religiosa. En el primer supuesto, se parte de la base que no cualquier actividad desempeñada en la entidad religiosa puede ser considerada como necesaria para el cumplimiento de la finalidad que persigue el empleador. En este orden de ideas, el "factor religioso" no se convierte en una

42 Cfr., Valdés Dal-Re (2006) p. 575. Véase también Fernández Márquez (2007) p. 102.

43 Cfr. Rojas Rivero (2008b) p. 34.

44 Cfr. Fernández Márquez (2007) p. 100.

45 Cfr., Irureta Uriarte (2003) p. 240. Véase también Precht Pizarro (2008a) p. 523.

46 Cfr., Baylos Grau (1980) p. 269. Un caso paradigmático, en esta línea, se produjo por ejemplo en Alemania cuando el Tribunal constitucional de dicho país validó el despido de un médico de un hospital católico "porque se había manifestado en la televisión y en la prensa abiertamente en contra de la doctrina de la Iglesia Católica acerca del derecho a la interrupción del embarazo" (véase Robbers (1996) p. 66). Con todo, y en relación con los centros docentes, la doctrina (GoÑ SEIN (1988) pp. 288 y 289) ha advertido que la pretensión de homogeneizar la vida privada al ideario religioso del empleador no puede ser aplicado de manera uniforme para todos los trabajadores. Debiera existir, en este sentido (tal como lo recalcan BaYlos GraU (1980) p. 263; De Otaduy Guerin (1986a) pp. 325 y 332; y Rodríguez-Piñero y Bravo-Ferrer (1983) pp. 379 y 380) una cierta gradación según los diferentes tipos de prestaciones de los trabajadores. Lo anterior cobra mayor relevancia si se considera que, en el caso chileno, ha sido el propio legislador quien ha considerado como datos sensibles de una persona aquellos antecedentes personales que se refieren a las creencias o convicciones religiosas (cfr. art. $2^{\circ}$, letra g, de la Ley $\mathrm{N}^{\circ} 19.628$, de 1999).

47 Cfr., De Otaduy Guerin (1986a) p. 316. Véase también Martin Valverde (2008b) p. 288. 
condición objetiva exigible para el normal desarrollo de la tarea ${ }^{48}$; ni tampoco se requiere un posicionamiento ideológico previo del trabajador ${ }^{49}$.

Distinta es la situación de aquellos trabajadores que desempeñan tareas o funciones conectadas con el ideario. Aquí se ha planteado la duda si el trabajador debe efectivamente identificarse con su empleador o bien mantener distancia de la misma (aun cuando se entiende que no puede confrontar directamente dicho ideario). Sobre el particular, la doctrina ha distinguido dos supuestos: (i) El primero se refiere a las denominadas teorías subjetivas según las cuales la comunión con el ideario por parte del trabajador resulta esencial tanto para constituir el vínculo como para mantenerlo en su desarrollo. Si este factor de identificación se pierde, entonces el empleador se encontraría facultado para poner término al contrato por causa imputable al trabajador; y (ii) El otro supuesto, vinculado a las teorías objetivas, parte de la base de que las tareas propagadoras del ideario religioso son parte esencial de las obligaciones laborales asumidas por el trabajador al momento de celebrar el contrato de trabajo. Lo anterior lo obligaría a adecuar su conducta al referido ideario, "y mientras lo haga no tiene por qué comulgar íntimamente con las creencias de su empleador" $"$.

La tendencia anterior ha ido cediendo paso, eso sí, a criterios más rigurosos en la calificación de conductas eventualmente confrontacionales con el ideario de la entidad religiosa. En efecto, actitudes de desafección del trabajador hacia el modelo de vida de su empleador religioso no constituyen, en sí mismos, una causa de incumplimiento que justifique el despido. En numerosos casos, se ha venido exigiendo también que la supuesta infracción implique un trastorno grave en el funcionamiento de la institución ${ }^{51}$.

\section{CONCLUSIONES}

La Iglesia y las entidades religiosas, en general, se presentan ante el mundo del Derecho como organizaciones destinadas a propagar una determinada imago mundi. Desde esta perspectiva, el sistema jurídico les reconoce autonomía para cumplir sus propios fines específicos y tolera la existencia de ordenamientos complementarios a los establecidos por el orden estatal los que son aplicables a sus integrantes.

Esta especial configuración afecta a las personas que colaboran con la Iglesia y las entidades religiosas en la propagación del ideario. Este ideario se alza como un requisito esencial de su constitución, y extiende su influencia sobre el contenido obligacional de los colaboradores. De esta manera, conductas que en otro tipo de organizaciones serían completamente irrelevantes, en el marco de la entidad religiosa adquieren un significado singular que modaliza las obligaciones del colaborador.

Dentro del ámbito organizativo de las entidades religiosas, es posible distinguir dos tipos de colaboradores. En primer lugar, destaca aquel que ostenta la calidad de religioso

48 Cfr., Goñi Sein (1988) pp. 284 y 285.

49 Cfr., Fernández López (1985) p. 430.

50 Cfr. Cavas Martínez (2011) p. 66.

51 Sobre el particular, véase VALDÉs DAL-Re (2006) p. 572. 
(o bien que presenta un estatus propio dentro de la institucionalidad religiosa). La intención de dicho colaborador es la de propagar el ideario, y difícilmente podría enrostrársele la calidad de trabajador propiamente tal de la organización religiosa. Más que un vínculo laboral, lo que allí existe es una ligazón religiosa (o incluso asociativa) que aleja cualquier posibilidad de construir un contrato laboral o de prestación de servicios civil. Distinto es el caso de los colaboradores laicos que, sin tener la calidad de religiosos, se insertan en el ámbito organizativo de la entidad a objeto de colaborar en la propagación del imago mundi, o simplemente para ejecutar tareas más bien secundarias del ideario que no requieren de una especial adhesión religiosa. En el caso de aquellos colaboradores que desempeñan labores conectadas con el ideario, lo más probable es que se configuren como trabajadores al estilo de la legislación laboral en el entendido de que el contenido obligacional del contrato se modalizado por el "factor religioso" de su empleador. Por el contrario, si el colaborador desempeña tareas irrelevantes para el cumplimiento del ideario, su prestación se regirá casi en exclusiva por las normas de la legislación laboral; aun cuando habrá que reconocer que igual pesan sobre dicho colaborador exigencias de no enfrentamiento con el ideario de la entidad religiosa.

\section{BIBLIOGRAFÍA CITADA}

Alberca de Castro, Juan Antonio (1999): Régimen juridico del ministro de culto en España y Francia (Granada, Editorial Comares).

Alonso Olea, Manuel, y Montoya Melgar, Alfredo (1995): Jurisprudencia Constitucional sobre Trabajo y Seguridad Social, T. XII (Madrid, Editorial Civitas, primera edición).

Álvarez Cortina, Andrés-Corsino (1998): "El tratamiento de las confesiones religiosas", en Martínez-Torrón, Javier (editor), La libertad religiosa y de conciencia ante la justicia constitucional (Granada, Editorial Comares).

Aparicio Tovar, Joaquín (1992a): "Empresas ideológicas y derechos fundamentales del trabajador”, en Aparicio, Joaquín, y Baylos, Antonio (directores), Autoridad y Democracia en la empresa (Madrid, Editorial Tecnos).

Aparicio Tovar, Joaquín (1980b): "Relación de trabajo y libertad de pensamiento en las empresas ideológicas", en AA. VV. Lecciones de Derecho del Trabajo en homenaje a los profesores Bayón Chacón y Del Peso Calvo (Madrid, Servicio de Publicaciones de la Facultad de Derecho de la Universidad de Madrid).

Aznar Gil, Federico R. (1986): "La retribución económica de los sacerdotes en el ordenamiento canónico español”, REDCO No 121, Vol. 43.

Badilla Poblete, Elvira (2008): "El concepto de libertad religiosa en algunos instrumentos internacionales sobre derechos humanos que vinculan jurídicamente al Estado de Chile", RCHD Vol. $35 \mathrm{~N}^{\circ} 2$.

Basdevant-Gaudemet, Brigitte (1996): "Estado e Iglesia en Francia”. Estado e Iglesia en la Unión Europea, en Robbers, Gerhard (Baden-Baden, Editorial Nomos).

Baylos Grau, Antonio (1980): "Despido de un profesor de religión en un colegio privado", RPS No 126. 
Blat Gimeno, Francisco R. (1986a): Relaciones laborales en empresas ideológicas (Madrid, Centro de Publicaciones Ministerio de Trabajo y Seguridad Social).

Blat Gimeno, Francisco R. (1990b): “Trabajos Amistosos”, en Borrajo Dacruz, Efrén (director), Comentarios a las Leyes Laborales. El Estatuto de los Trabajadores, T. I (Madrid, Editorial de Derecho Reunidas.

Borrajo Dacruz, Efrén (1988): "Régimen jurídico aplicable al personal eclesiástico que presta servicios docentes en un centro privado dependiente de la entidad a la que pertenece”, EE No 246, Vol. 63.

CaAmaño Rojo, Eduardo (2006): "La eficacia de los derechos fundamentales en las relaciones laborales y su reconocimiento por la Dirección del Trabajo” XXVII.

Calvo Gallego, Francisco Javier (1995): Contrato de trabajo y libertad ideológica (Madrid, Consejo Económico y Social).

Cavas Martínez, Faustino (2011): “Libertad ideológica y contrato de trabajo”, en Sánchez Trigueros, Carmen (directora): Libertad de empresa y poder de dirección del empresario en las relaciones laborales. Estudios ofrecidos al profesor Alfredo Montoya Melgar (Pamplona, Editorial Aranzadi-Thomson Reuters, primera edición).

Contreras Mazario, José María (1991): "La igualdad y la libertad religiosas en las relaciones de trabajo", DA T. XVIII.

Cortínez Castro, S.J., René (2010): coordinador: Derecho Eclesiástico Chileno, normas concordadas y comentadas (Santiago, Ediciones UC, Santiago).

Dëubler, Wolfang (1994): Derecho del Trabajo (trad. de María Paz Acero Serna y Pío Acero López, Madrid, Centro de Publicaciones Ministerio de Trabajo y Seguridad Social).

De Otaduy Guerin, Jorge (1986a): "Las empresas ideológicas: aproximación al concepto y supuestos a los que se extiende", $A D E E$ Vol. II.

De Otaduy Guerin, Jorge (1991b): "Libertad religiosa y contratación del profesorado en centros concertados", $A L$ No 33.

De Otaduy Guerin, Jorge (1993c): Régimen jurídico español del trabajo de eclesiásticos y de religiosos (Madrid, Editorial Tecnos).

Del Peso y Calvo, Carlos (1966): "El sacerdote, en función de su sagrado ministerio, no goza del concepto legal de trabajador”, RISS No 2.

Díez-Picazo, Luis María (2005): Sistema de derechos fundamentales (Madrid, Editorial Thomson-Civitas, segunda edición).

Fernández-Coronado González, Ana (1995): “Confesión religiosa”, en Montoya MelGar, Alfredo (director), Enciclopedia Jurídica Básica, Vol. I (Madrid, Editorial Civitas, primera edición).

Fernández López, María Fernanda (1985): "Libertad ideológica y prestación de servicios", $R L$ T. II.

Fernández MÁrquez, Óscar (2007): "Libertad religiosa y trabajo asalariado: condiciones y criterios de articulación”, REDT $\mathrm{N}^{\circ} 133$.

Fontes Bastos, María Dolores (1989): “Servicios domésticos prestados a religiosos por familiares", REDT No 40.

Gil y Gil, José Luis (2003): Principio de la buena fe y poderes del empresario. Consejo Andaluz de Relaciones Laborales, Sevilla. 
Goñ SeIn, José Luis (1988): El respeto a la esfera privada del trabajador (Madrid, Editorial Civitas, primera edición).

Irureta Uriarte, Pedro (2003): "Las organizaciones de tendencia ante el Derecho", PS Vol. XVII Nº 2 .

Klenner Gutiérrez, Arturo (2007): Derecho del Trabajo y Seguridad Social del clero y los religiosos de la Iglesia católica en la legislación chilena. Utopía o desafio (Santiago, Editorial LexisNexis, primera edición).

López Alarcón, Mariano (1989): "Actitud del Estado ante el factor social religioso", ADEE Vol. V.

Maldonado Montoya, Juan Pablo (2012): "Matrimonio civil e idoneidad del profesor de religión", REDT $\mathrm{N}^{\circ} 153$.

Martin Valverde, Antonio (2002a): "Fronteras y 'zonas grises' del Derecho del Trabajo en la jurisprudencia actual (1980-2001)”, RMTI N 38.

Martin Valverde, Antonio (2008b): "Libertad religiosa, contrato de trabajo y docencia de religión”, REDT Nº 138 (2008).

Moreno Anton, María (1989): "Vida privada de los docentes e ideario del centro educativo en el Derecho español", ADEE Vol. V.

Moreno Botella, G. (1987): "El carácter propio de las entidades religiosas y sus consecuencias en el Derecho Laboral español”, REDCA No 123.

Moro Almaraz, María Jesús (1986): "Derecho de expresión y libertad ideológica en el ámbito laboral", RL, T. I.

Olmos Ortega, María Elena (2001): "Laicos y oficios eclesiásticos", REDCA Nº 151, Vol. 58.

Precht Pizarro, Jorge (2008a): "Idoneidad del profesor de religión”, RCHD Vol. $35 \mathrm{~N}^{\circ} 3$.

Precht Pizarro, Jorge (2000b): "La libertad religiosa", RDDPUCV Vol. XXI.

Precht Pizarro, Jorge (1989c): "La personalidad jurídica de la Iglesia Católica y de los entes eclesiásticos católicos ante el Derecho del Estado de Chile", RCHD Vol. 16.

Prieto SAnchis, Luis (1988): "Posición jurídica de las asociaciones religiosas en el Derecho español”, ADEE Vol. IV.

Robbers, Gerhard (1996): "Estado e Iglesia en la República Federal de Alemania”, en Robbers, Gerhard (editor), Estado e Iglesia en la Unión Europea (Baden-Baden, Editorial Nomos).

Rodríguez-Piñero y Bravo-Ferrer, Miguel (1983): "No discriminación en las relaciones laborales", en Borrajo Dacruz, Efrén (director), Comentarios a las Leyes Laborales. El Estatuto de los Trabajadores, T. IV (Madrid, Editorial de Derecho Reunidas).

Rodríguez-Piñero y Bravo-Ferrer, Miguel, y Fernández López, María Fernanda (1986): Igualdad y discriminación (Madrid, Editorial Tecnos).

Rojas Rivero, Gloria (1991a): La libertad de expresión del trabajador (Madrid, Editorial Tecnos).

Rojas Rivero, Gloria Pilar (2008b): Cláusula de conciencia y extinción del contrato (Madrid, Editorial Thomson-Aranzadi, primera edición).

Salinas Araneda, Carlos (2009): "El derecho eclesiástico del Estado de Chile al tiempo del bicentenario: logros y dificultades", RDDPUCV $\mathrm{N}^{\circ} 33$ (2009). 
San Millan Novau, Ingrid (1998): "Contrato de trabajo y descanso religioso semanal", en Martínez-Torrón, Javier (editor), La libertad religiosa y de conciencia ante la justicia constitucional (Granada, Editorial Comares).

Ugarte Cataldo, José Luis, "La tutela de derechos fundamentales y el Derecho del Trabajo: de erizo a zorro". RDD Vol. XX N² 2 (2007).

VALDÉS DAL-RE, Fernando (2006):, "Libertad religiosa y contrato de trabajo", en CASAS Baamonde, Emilia; Durán López, Federico y Cruz Villalón, Jesús (directores), Las transformaciones del Derecho del Trabajo en el marco de la Constitución española. Estudios en homenaje al profesor Miguel Rodríguez-Piñero y Bravo-Ferrer (Madrid, Editorial La Ley).

Varas Braun, Juan Andrés (2005): "Sentencia sobre responsabilidad civil del obispo por los hechos de sus clérigos (Corte Suprema)", $R D D$ Vol. XVIII N ${ }^{\circ} 1$.

Vicente Cantin, Luis (1990): Naturaleza, contenido y extensión del derecho de libertad religiosa (Madrid, Editorial Civitas, primera edición).

Zabalza Bas, Ignacio (1986):Las confesiones religiosas en el Derecho eclesiástico alemán (Barcelona, Editorial Bosch).

\section{NORMAS CITADAS}

Artículo 3 de la Ley $\mathrm{N}^{\circ}$ 19.638, de 14 de octubre de 1999, que Establece normas sobre la Constitución Jurídica de las Iglesias y Organizaciones Religiosas.

Artículo $4^{\circ}$ de la Ley $N^{\circ} 19.638$, de 14 de octubre de 1999, que Establece normas sobre la Constitución Jurídica de las Iglesias y Organizaciones Religiosas.

Artículo 14 de la Ley N 19.638, de 14 de octubre de 1999, que Establece normas sobre la Constitución Jurídica de las Iglesias y Organizaciones Religiosas.

Artículo 20 de la Ley $\mathrm{N}^{\circ}$ 19.638, de 14 de octubre de 1999, que Establece normas sobre la Constitución Jurídica de las Iglesias y Organizaciones Religiosas.

Artículo $1^{\circ}$ del Código del Trabajo (DFL N ${ }^{\circ} 1$ de 1994)

Artículo $2^{\circ}$ del Código del Trabajo (DFL Nº 1 de 1994)

Artículo $3^{\circ}$ del Código del Trabajo (DFL Nº 1 de 1994)

Artículo $4^{\circ}$ del Código del Trabajo (DFL Nº 1 de 1994)

Artículo $5^{\circ}$ del Código del Trabajo (DFL Nº 1 de 1994)

Artículo $7^{\circ}$ del Código del Trabajo (DFL Nº 1 de 1994)

Artículo $8^{\circ}$ del Código del Trabajo (DFL N ${ }^{\circ} 1$ de 1994)

Artículo $9^{\circ}$ del Código del Trabajo (DFL N ${ }^{\circ} 1$ de 1994)

Artículo 547 del Código Civil

Artículo 2322 del Código Civil

Artículo 19 N 6 de la Constitución Política de la República

Artículo 19 N $^{\circ} 11$ de la Constitución Política de la República

Canon 231 del Código Canónico, de 25 de enero de 1983

Canon 1286 del Código Canónico, de 25 de enero de 1983 


\section{JURISPRUDENCIA JUDICIAL CITADA}

Obra de Don Bosco (1956): CORTE SUPREMA de 22 de junio de 1956 (Recurso de Queja). Repertorio de Legislación y Jurisprudencia Chilenas. Código del Trabajo (1958) (Santiago, Editorial Jurídica de Chile), p. 7.

Pizarro O., Jaime (1995): CORTE DE APELACIONES DE SANTIAGO de 3 de octubre de 1995 (Recurso de Apelación). RDJ T. XCII (1995), I, sección tercera, pp. 164-166.

Iglesia de Dios en Chile con Ministro de Justicia (2001): CORTE DE APELACIONES DE CONCEPCIÓN de 14 de junio de 2001 (Reclamación artículo 11 de la Ley $\mathrm{N}^{\circ}$ 19.638). RDJ T. XCVIII (2001), II, sección quinta, pp. 150-153.

Olmedo Bustos y otros contra el Estado de Chile (2001): Corte Interamericana de Derechos Humanos de 5 de febrero de 2001 (Denuncia). No. 11.803, en www.corteidh.or

Torres Acuña, Aliro, y otros, con Alcalde de la Municipalidad de San Pedro (2002): CORTE DE APELACIONES DE CONCEPCIÓN de 4 de marzo de 2002 (Recurso de Protección). RDJ T. XCIX (2002), II, sección quinta, pp. 217-226.

Contra José Andrés Aguirre Ovalle (2005): CORTE SUPREMA de 5 de enero de 2005 (Recurso de Casación en la Forma y en el Fondo). Causa Ingreso Corte $N^{\circ} 3640-2004$, en www.poderjudicial.cl

Pilmaiquén S.A. (2005): CORTE DE APELACIONES DE VALDIVIA de 5 de mayo de 2005 (Recurso de Protección). Causa Ingreso Corte N²303-2005, en www.poderjudicial.cl

Requerimiento de parlamentarios y otros para que se declare la inconstitucionalidad del Movimiento Patria Nueva Sociedad (2006): TRIBUNAL CONSTITUCIONAL de 2 de junio de 2010 (Requerimiento de inconstitucionalidad). ROL N 567-2006, en www. tribunalconstitucional.cl

Michel Salazar, Juan, con Diario La Tercera (2007): CORTE DE APELACIONES DE SANTIAGO de 24 de enero de 2007 (Recurso de Protección). RDJ T. CIV (2007), sección quinta, pp. 636-641.

Rubio Sánchez, Patricia, con Congregación Hermanas de la Caridad (2010): CORTE SUPREMA DE 18 de marzo de 2010. Causa Ingreso Corte $N^{\circ} 322-2010$, en www.poderjudicial.cl

Valdés, María Hortensia, con Congregación Instituto Hijas de María (2011): SEGUNDO JUZGADO DE LETRAS DEL TRABAJO DE SANTIAGO de 26 de enero de 2011 (Demanda en procedimiento de aplicación general). Causa RIT $N^{\circ} \mathrm{O}-3735-2010$, en www.poderjudicial.cl

Villagra Muñoz, Ismael, con Congregación Salesiana Instituto Don Bosco (2011): SEGUNDO JUZGADO DE LETRAS DEL TRABAJO DE SANTIAGO de 12 de agosto de 2011 (Demanda de Tutela Laboral). Causa RIT N T-239-2011, en www.poderjudicial.cl

Carocca con Fundación Educacional Colegio San Pedro Nolasco (2012): CORTE DE APELACIONES DE CONCEPCIÓN de 13 de abril de 2012 (Recurso de Nulidad). Causa Ingreso Corte $\mathrm{N}^{\circ}$ 42-2012, en www.poderjudicial.cl 


\section{JURISPRUDENCIA ADMINISTRATIVA CITADA}

Dictamen $\mathrm{N}^{\circ}$ 0058/001, de 7 de enero de 2010, de la Dirección del Trabajo, en www. dt.gob.cl

Dictamen No 3599 de la Dirección del Trabajo, de 16 de mayo de 1991, www.dt.gob.cl

Dictamen $N^{\circ}$ 649/22, de 9 de febrero de 2005, www.dt.gob.cl

Dictamen $N^{\circ} 1036$, de 19 de abril de 1979, www.dt.gob.cl

Dictamen $\mathrm{N}^{\circ} 11.442$, de 4 de octubre de 1985, www.dt.gob.cl

Dictamen N 12.379, de 1 de julio de 1998, de la Superintendencia de Seguridad Social, en Klenner Gutiérrez (2007) pp. 216 y ss. 
